\title{
Pazarlama Literatüründe Elektronik Ağıdan Ağıza İletişimin Bibliyometrik Analizi (Bibliometric Analysis of Electronic Word-Of-Mouth Communication in Marketing Literature)
}

\author{
Ayşe EREN iD a Duygu EREN iD b \\ a Akdeniz Üniversitesi, Antalya, Türkiye. ayseeren@akdeniz.edu.tr \\ b Nevşehir Hacı Bektaş Veli Üniversitesi, Nevşehir, Türkiye. deren@nevsehir.edu.tr
}

\begin{tabular}{l} 
MAKALE BİLGİsi \\
\hline Anahtar Kelimeler: \\
Elektronik Ağıdan Ağıza \\
İletişim \\
Bibliyometrik Analiz \\
eWOM
\end{tabular}

Gönderilme Tarihi 18 Mayıs 2020

Revizyon Tarihi 3 Temmuz 2020

Kabul Tarihi 2 Ağustos 2020

Makale Kategorisi:

Araştırma Makalesi

\section{ÖZET}

Amaç - Bilimsel araştırmaların sayısının artması ve bilimin küreselleşmesine paralel olarak, bibliyometrik çalışmalar önemli bir araştırma alanı haline gelmiştir. Bu çalışmanın amacı elektronik ağızdan ağıza iletişim konusunda yapılmış araştırmaları bibliyometrik yöntem ile incelemektir.

Yöntem - "EWOM" anahtar kelimesi Web Of Science'ın tüm dizinlerinde aratılmış, başlık ve anahtar kelimelerde ifadeyi içeren tüm yayınların kayıtları elde edilerek VOSVIEWER programı aracılığı ile verilerin analizi yapılmıştır. Araştırmada makale sayısı, atıf sayısı, en çok yayın yapan üniversiteler ve yazar ağ analizi şeklindeki bibliyometrik göstergeler kullanılarak Web of Science'ta (WoS) 2006 ile 2018 yılları arasında yer alan toplam 439 makale incelenmiştir.

Bulgular - Çalışmanın sonuçları, elektronik ağızdan ağıza iletişim alanındaki öncü yazar ve araştırmaları belirlemek ve araştırmacılara yeni çalışmaları için literatür taraması ve konu belirleme noktalarında faydalı olabilir. Sonuçlar incelendiğinde, toplam atıf sayısının 8645 ve 2006-2018 yılları arasında yayınlanmış toplam makalelerin ortalama atıf sayısının 19,96 olduğu tespit edilmiştir. Makalelerin h-indeksi 45 olarak tespit edilmiştir. Litvin, Goldsmith ve Pan'ın 2008 yılında yazdıkları elektronik ağızdan ağıza konulu makaleleri 739 atıf ile araştırmada incelenen en çok atıf almış makale özelliği taşımaktadır. 16 Makale ile alana en fazla yayın gönderen organizasyon State University System of Florida'dır. Ayrıca makalelere konu olmuş ve üzerine en çok makale yazılmış araştırma konusu 'İ̧̧ Ekonomisi"dir.

Tartışma - Çalışma elektronik ağızdan ağıza iletişimin pazarlamanın dışındaki alanlara da konu olduğunu göstermektedir. 2000'li yılların başından bu yana internetin yaygınlaşması ve sosyal medyanın ortaya çıkışı ile elektronik ağızdan ağıza iletişim araştırmalara konu olmaya başlamıştır. Her geçen yıl elektronik ağızdan ağıza konulu araştırmalarda artış gözlenmiştir. Türkiye'den konu ile alakalı uluslararası literatüre öncü bir çalışma kazandırılmamıştır.

\section{ARTICLE INFO} ABSTRACT

Keywords:

Electronic Word of Mouth

Bibliometric Analysis eWOM

Received 18 May 2020

Revised 3 July 2020

Accepted 2 Auğust 2020

Article Classification:

Research Article
Purpose - In parallel with the increase in the number of scientific researches and the globalization of science, bibliometric studies have become a significant research area. The aim of this study is to investigate the studies on electronic word of mouth (eWOM) with a bibliometric method.

Design/methodology/approach - In the research, a total of 439 articles in the Web of Science (WoS) between the years 2006 and 2018 were analyzed using bibliometric indicators such as the number of articles, the number of citations, the most publishing universities, and author network analysis.

Findings - The results of the study may be useful in identifying the leading authors and researches in the field of eWOM and in the literature review and topic identification stages for researchers for their new studies. As for the results, the total number of citations is 8645 and the average number of citations is 19,96. The h-index of the articles has been observed as 45. The article of Litvin, Goldsmith and Pan which was written in 2008 about eWOM is rated as the most cited article examined in the research with 739 citations. The organization that has sent the most articles to the field with 16 articles is the State University of Florida. In addition, the research topic which has been the subject of articles and the mostly-written on is Business Economics.

Discussion - The study shows that electronic mouth-to-mouth communication has been discussed in different academic areas not just im marketing. With the spread of the internet and the emergence of social media since the beginning of the 2000s, academics paid attention to electronic word of mouth communication in qualitative and quantitavie researches. In last two decades every year researches on eWOM has increased. International literature has not gained pioneering researches from Turkey. 


\section{GİRISS}

Son on yılda gerçekleşen internet kullanımındaki artış insan davranışını ve iletişimini birçok yönden etkilemektedir. Bireyler veya kurumlar arasındaki iletişimin gerçekleştiği platformlardan biri sosyal medyadır. Yeni iletişim kanallarından biri olan sosyal medya, tüketicilerin kullandıkları ürünler hakkındaki düşüncelerini ve deneyimlerini paylaşttğı ve diğer tüketicileri ve işletmeleri farklı şekillerde etkilediği bir ortamdır. Yeni iletişim biçimlerinin tüketicilerin algıları, tutumları ve davranışları üzerindeki etkisi araştırmacıların dikkatini çekmektedir. Güncel gelişmelere bağlı olarak son yıllarda pazarlama ve bilişim teknolojilerinde elektronik ağızdan ağıza iletişim ile ilgili araştırmaların ve yayınların sayısında önemli ölçüde artış yaşanmıştır.

Elektronik ağızdan ağıza iletişim (Electronic Word of Mouth/eWOM) geleneksel ağızdan ağıza iletişimin teknolojik bir türevi olarak ifade edilmektedir (Hennig-Thurau, Gwinner, Walsh \& Gremler, 2004). İnternetin yaşamın her alanına dahil olmasıyla birlikte geleneksel ağızdan ağıza iletişimin yanında elektronik ağızdan ağıza iletişim kullanılmaya başlamıştır (Daugherty \& Hoffman, 2014). Carl, (2006) elektronik ağızdan ağıza iletişimi bir markanın, bir malın veya bir hizmetin özellikleriyle ilgili olarak iki veya daha fazla kişinin değerlendirmelerinin internette gayri resmi şekilde yayılımı olarak tanımlamaktadır. Tüketici değerlendirmelerinin mal ve hizmetlerle ilgili bilgi verme ve öneri sunma olmak üzere iki rolü vardır (Park, Lee \& Han, 2007). İnternet kullanıcı sayısının dünya genelinde artmasıyla birlikte sanal platformlarda bilgi paylaşımı daha kolay ve daha hızlı bir şekilde gerçekleşmektedir. Sözü edilen platformlar ve imkan verdiği paylaşımların artması, yeni olguların ortaya çımasına neden olmuş ve bu değişim bilim insanlarının ilgisini çekmeye başlamış ve araştırmalara konu olmuştur. Çalışmaların sayısının sürekli artması tanzimini ve analizini gerektirdiğinden, eWOM konusunu ele alan araştırmaların bibliyometrik yöntemlerle incelenmesi bir ihtiyaç olarak değerlendirilmektedir.

Belirli bir araştırma disiplini veya araştırma konusu üzerinde mevcut olan bilimsel literatürün çoğu zaman dağınık yapısı araştırmacıların ve uygulayıcıların ilgili bilgileri yapısal bir şekilde görebilmelerini zorlaştırmaktadır (Rodrigues, van Eck, Waltman, \& Jansen, 2014). Bibliyometrik yöntemler, yazarların, dergilerin, ülkelerin ve öncülerin performanslarını ve araştırma modellerini değerlendirmek ve bunlar arasındaki işbirliği kalıplarını belirlemek ve ölçmek için kullanılabilir (Li \& Zhao, 2015).

Günümüzde, bilimsel üretimin niteliğini ve miktarını ölçmek, hemen hemen her araştırma değerlendirme kararının büyük ölçüde ilgili araştırmacıların bilimsel değerlerine bağlı olmasından dolayı önemli bir gerekliliktir. Bunu yapmak için literatürde birçok farklı gösterge önerilmiştir. Bir araştırma alanını incelemek için iki ana bibliyometrik prosedür tanımlanmıştır: performans analizi ve bilim haritası. Performans analizi, bilimsel aktör gruplarını (ülkeler, üniversiteler, araştırmacılar) ve faaliyetlerinin bibliyografik veriler temelinde etkilerini değerlendirmeyi amaçlamaktadır. Bilim haritaları, sayısız veriyi, görünür aykırı noktaları, kümeleri ve eğilimleri etkili bir şekilde ayırt edilmesine olanak tanıyan şekillerde resmeden, çok miktarda veriye görsel ara yüzler olarak hizmet etmektedir. Bir bilim haritası, bir bilim alanının iki veya üç boyutlu temsilidir; haritadaki öğelerin, coğrafi haritadaki şehirler gibi, haritadaki temalara ve konulara atıfta bulunduğu bir bilim manzarasıdır (Noyons, 2001).

Bibliometrik yöntemler son yıllarda bilim insanları tarafından ilgi görmüş ve belirli bir derginin veya veri tabanının yayın özelliklerini ve etkisini analiz etmede etkili olduğu kanıtlanmıştır. Literatürde VOSviewer yazılımı kullanarak yapılmış çalışma sayısı oldukça kısıtlıdır. Scopus veri tabanında taranan Hemşirelik Yönetimi Dergisi'nin ilk sayısından (1993) 2018'e kadar olan gelişimsel durumu (Su ve ark., 2020), ramazan oruç ve sağlık alanında yüzlerce alıntı yapılan ilk yayınların tespitini ve analizini (Hussain ve ark., 2020), yıllık yayın sayısı, atıflar, en çok atıf yapılan makaleler, en üretken yazarlar ve The Tourism Recreation Research'de belge yayınlayan kurum ve ülkelerin çeşitliliği (Vishwakarma ve Mukherjee 2019), 1990-2015 yılları arasında endüstriyel pazarlama araştırmaları (Valenzuela Fernandez ve ark. 2019), Soft Computing dergisini yöneten öncü eğilimler (Merigo ve ark. 2018), makale alıntılar ve h-endeksi (Blanco-Mesa ve ark. 2017) ve Computers \& Industrial Engineering dergisinin 1976 ve 2015 yılları arasında derginin etki, konular, üniversiteler ve ülkeler açısından önde gelen eğilimlerini (Cancino ve ark. 2017) belirlemeye yönelik VOSviewer yazılımı desteği ile araştırmalar yapılmıştır. Ancak, araştırmalar dahilinde, elektronik ağızdan ağıza iletişim konulu yayınların analiz edilmesi için haritaların kullanıldığı bibliometrik yaklaşımı tercih eden makaleye rastlanmamıştır. Bu durum çalışmaya özgünlük katmaktadır. Çalışmada alanında önemli ve etkili 


\section{A. Eren - D. Eren 12/3 (2020) 2515-2530}

dergilerden oluşan Web of Science veri tabanında elektronik ağızdan ağıza iletişimin gelişimsel durumu hakkında bibliyometrik bir bakış açısı sunabilmek için "eWOM" kelimesi taranmıştır. Sadece kısaltmanın taranmasındaki amaç çalışmaların tamamında elektronik ağızdan ağıza iletişim teriminin birkaç kullanımdan sonra kısaltma şeklinde kullanılmaya başlanmış olmasıdır. Bütün çalışmalarda özellikle özette ve/veya anahtar kelimelerde elektronik ağızdan ağıza iletişim teriminin kısaltma olarak görmekteyiz. İlk makalenin 2006 yılında yazıldığı tespit edilmiştir. Tarama sırasında çeşitli kısıtlamalar yapılmıştır. Bu kısıtlamalardan biri belge türü olarak makale seçilmesi olmuştur ve bu kısıtlama ile bütün veri tabanında tespit edilen 439 makale çalışmada incelenmiştir. Bilgisayar destekli VOSviewer yazılımı kullanılarak yapılan bibliyometrik analizler sonucunda bilim haritaları elde edilmiştir. Bibliyometrik analiz, yayınların dinamik eğilimlerini araştırmak ve bu konudaki en etkili yazarları, kurumları, atıf bilgilerini ve araştırma dilini belirlemek için kullanılmıştır.

\section{YÖNTEM}

Web of Science, araştırmacılar tarafından yüksek kalite standartlarına sahip olmasından dolayı tanınan uluslararası bir dijital bibliyometrik platformdur (Merigó, Mas-Tur, Roig-Tierno \& Ribeiro-Soriano, 2015; Nebioğlu, 2019) ve farklı yayın türlerini ve dergileri araştırmak ve değerlendirmek için ana araçlardan biri haline gelmiştir (Thelwall, 2008). Bibliyometrik analiz yapmak isteyen araştırmacılara Web of Science, ilgili indekslerde yer alan yayınların özet, kaynakça, alıntı sayısı, yazarların listesi, kurumlar, ülkeler ve derginin etki faktörleri dahil olmak üzere bir dizi meta veri sağlamaktadır. Söz konusu veriler daha sağlıklı analizleri mümkün kılmaktadır. Dolayısı ile WoS Core Collection veri tabanından istenilen etiketlere göre arama yapabilir ve veriler indirilebilir. Ayrıca, yayınlanma yılı, yayınlanma dili, doküman tipi ve atıf dizini gibi kriterlerin aramada uygulanabilmesi mümkündür.

Araştırma kapsamında verilerin toplanması Web of Science'ın bütün dizinlerinde yapılmıştır. Arama stratejisine göre araştırma makaleleri için yayın yılı sınırlaması konulmadan "eWOM" anahtar kelimesi ile makalelerin incelenmesi yolu tercih edilmiştir. Makalelerin tamamı indirilmiş olup incelenen makalelerin çoğunda electronic word of mouth kelimesinin makalelerin ilerleyen paragraflarında kısaltması olan eWOM'un kullanıldığı gözlemlenmiştir. Bu sebeple veri tabanında terimin kısaltması taranmıştır. Taranan veri tabanında kısaltmanın kullanılmadığı makalelerde mevcut olup çalışmada inceleme dışı bırakılmıştır. Bu araştırmada sadece eWOM ifadesinin başlıkta veya anahtar kelimede kullanıldığı yayınlar incelenmiştir. Veriler daha sonra başka analizler yapmak için VOSviewer yazılımı ile uyumlu çalışabilecek dosya formatlarında kaydedilmiştir. VOSviewer yazılımının veri analizi seçeneklerinde anahtar kelimelerin harita ve kümelerinin elde edilmesini sağlamak için, bütün anahtar kelimeler seçilmiştir. Her bir veri seti, bütün yıllardaki araştırma konularını yansıtacak anahtar kelimeleri elde etmek için analize tabi tutulmuştur ve böylece zaman içinde alanın gelişimi ortaya çıkarılmıştır. Çalışmada VOS viewer yazılımının kullanılma sebebi grafiksel analiz, bibliyografik eşleme, birlikte alıntılama, alıntı yapma, yazarların ve anahtar kelimelerin birlikte haritalandırılmasına olanak vermesidir.

Veriler, tamamlayıcılık amaçlı ağ haritalarında ve tablolarda sunulmuştur. Tablolarda yalnızca en sık kullanılmış on anahtar kelimeye yer verilirken, ağ haritalarında anahtar kelimelerinin ortaya çıkma ve bağlantı özelliklerine ilişkin yoğunluk temelini gösteren bir şekil sunulmuştur. Tablolar ve haritalar birlikte okunduğunda, ilk taramada yayın yılı sınırlaması konulmadan makale araştırması yapılmasına rağmen ilk elektronik ağızdan ağıza iletişim makalesinin 2006 yılında yayınlandığı belirlenmiştir. Bu nedenle 2006 yılı ve belge türü kısıtlaması getirilerek yeniden taranmıştır. Herhangi bir kısıt olmadan yapılan ilk taramada elektronik ağızdan ağıza iletişim ile ilgili 613 yayın tespit edilmiştir. Belge türü (makale) kısıtı getirilerek yapılan ikinci taramada konuya ilişkin 439 makaleye ulaşılmış ve bu yayınların hepsi bibliyometrik analize dahil edilmiştir. 2006 ile 2018 yılları arasındaki araştırmalar elektronik ağızdan ağıza iletişim alanının evrimi üzerinde bir tablo ortaya çıkarmaktadır. Çalışmanın amaçları doğrultusunda, iki 5 yıllık ve bir 3 yıllık sınırlamaları ile (2006-2010; 2011-2015; 2016-2018) VOSviewer harita ve tabloları sunulmuştur. Ayrıca makalenin bir diğer amacı olan atıf analizlerinin yapılabilmesi için 439 makalenin toplam atıf ve ortalama atıf sayıları sunulmuştur. Dergilerin, makalelerin ve yazarların yayın kalitesini belirlemek amacı ile ileri sürümüş h-indeks rakamları yine atıf analizi doğrultusunda açıklanmıştır. 


\section{BULGULAR}

Bulgular kısmında öncelikle yayınlanan doküman sayısı, alıntılanma sayısı, analiz edilen h-endeksi ve bu göstergelerden elde edilen çeşitli oranlar şeklindeki bibliyometrik göstergelere dayanan performans analizi sonuçları verilmektedir. İkinci adımda bilim haritaları sunulmuştur.

Tablo 1 ve Grafik 1'de incelenen makalelerin yıllara göre dağılımı yer almaktadır. Şekilde ve tabloda görüldügü üzere konu ile ilgili yayın sayısının yıllar itibariyle arttığ yılında yalnızca bir makale bulunurken 2018 yılı içinde ise makale sayısı 102'ye yükselmiştir. 2006-2010 yılları arasında 22, 2015-2018 yılları arasında toplam 321 makale yayınlanmıştır. Elektronik ağızdan ağıza iletişim ile ilgili son dört yılda yayınlanmış toplam makale sayısı ilk 5 yıllık süreçteki toplam makale sayısının yaklaşık 15 katıdır. Analiz sonucunda son yıllarda konuya akademisyenlerin ilgisinin arttığını söylemek mümkündür. Makale sayısı arttıkça makalelere olan atıfta doğru orantılı artmıştır.

Atıf sayılarına dayalı olan bibliometrik göstergeler, ikincil veri olduğundan uzun veri toplama işlemlerine gerek kalmadığı için alternatif bir araştırma yolu sunmaktadır (Smith, 1981). Ayrıca bir araştırma alanının önemini ve etkisini vurgulamanın yolu, kendi alanında yayınlanmış eserlerdeki alıntıların sayısıdır.

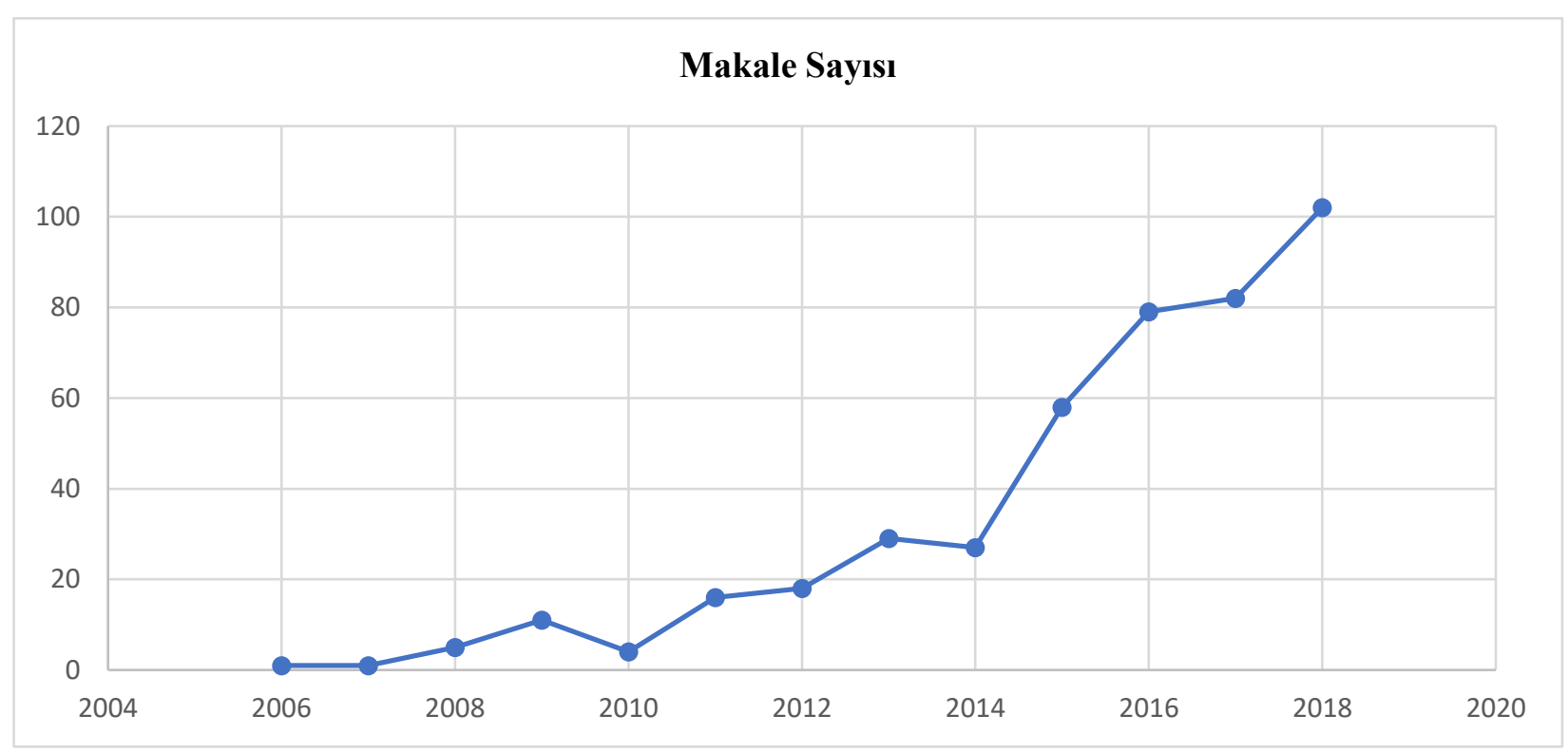

Grafik 1: Yıllara göre makale sayıları

Tablo 2 ve Grafik 2' de eWOM alanına ilişkin yapılan yayınların alıntılanma sayılarının yıllara göre dağılımı verilmiştir. Görüldüğ̈̈ üzere alana ilişkin yayınların toplam alıntılanma sayısı 8786'dır. İncelenen bütün makalelerden 2018'de 2260, 2017'de 2155, 2016'da 1455, 2015'de 1025, 2014' de 653, 2013' de 462,2012' de 295, $2011^{\prime}$ de 192, 2010'da 91, 2009'da 47, 2008' de 7, 2007'de 1ve 2006'da 2 alıntı yapılmıştır. 2014-2015-2016-20172018 yılları içerisindeki atıf sayısı toplam 7548 atıf toplam atfın \%85'inden fazlasına denk gelmektedir. Yıllar geçtikçe eWOM çalışmalara konu olmaya artarak devam etmiştir. 


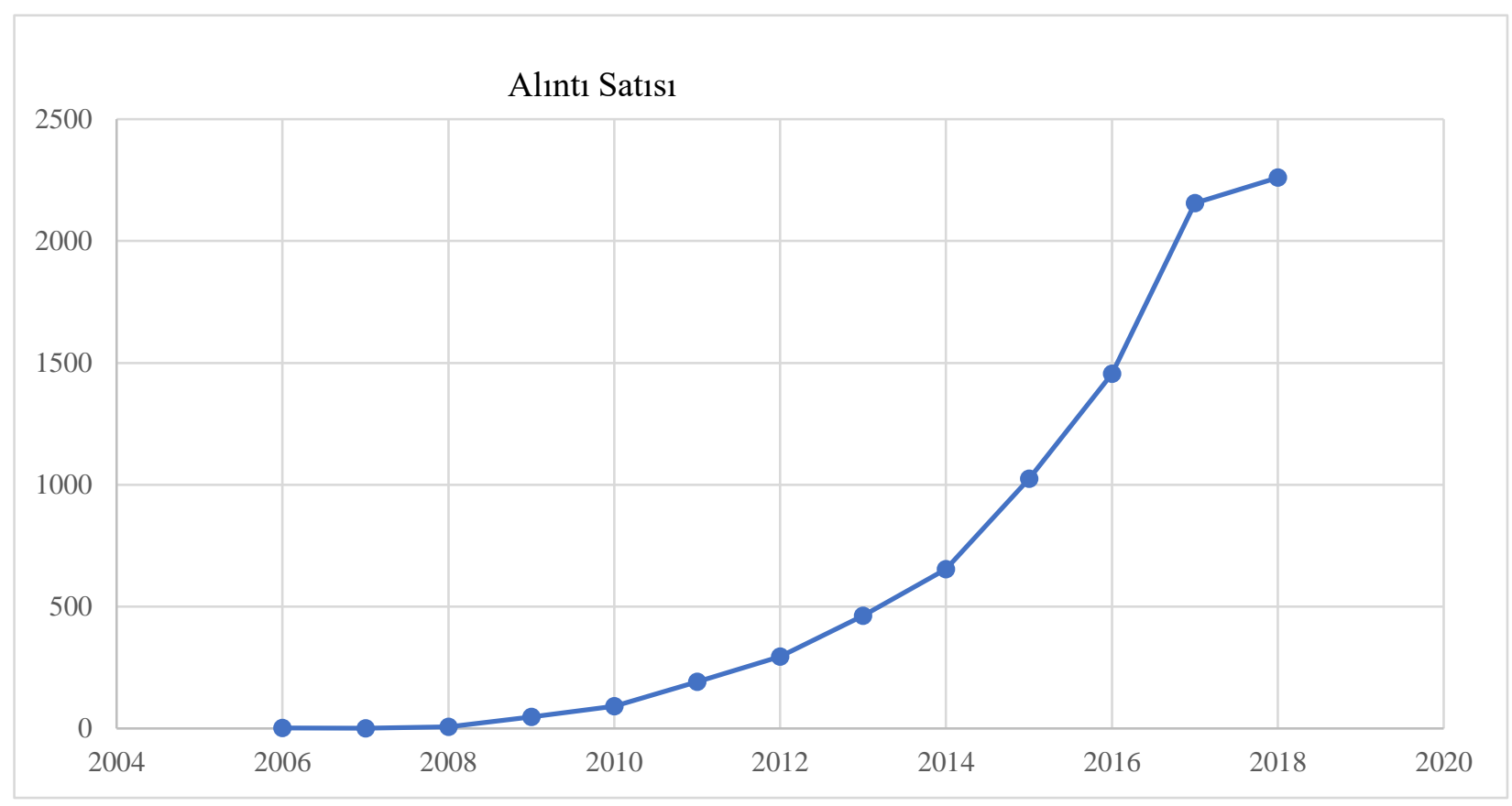

Grafik 2. Yıllara göre atıf sayıları

H-dizini fizikçilerin performansını ölçmek için daha iyi bir çözüm bulmak üzere J.E. Hirsch tarafından tasarlanmıştır, ancak diğer alanlarda da faydalı olduğu kanıtlanmıştır (Tunç, 2015). Böylece, diğer bilimsel alanlar için önerilmiştir (Hirsch, 2005). Web of Science'da eWOM kelimesi ile aranan makalelerin h-dizini değeri, yukarıda belirtilen sayıya göre azalan düzende sıralanmış bir yayın listesine dayanmaktadır. H-dizini, her biri en az $\mathrm{h}$ kez alıntılanmış olan $\mathrm{h}$ sayıda makalelerinin olduğu anlamına gelir. Bu çalışmaya göre toplam makalelerin içerisinde 45 makale en az $45 \mathrm{kez}$ alıntılanmıştır. H-dizini dışında ortalama atıf ve toplam atıf sayıları da önemlidir. Ortalama atıf bütün makalelere yapılmış atıfların makale sayısına bölünmesi ile ortaya çıkmaktadır. Çalışmada incelenmiş toplam makale sayısı 439 olup, toplam atıf sayısı 8645 ve ortalama atıf sayısı $19,96^{\prime}$ dır.

Tablo 3. Makalelerin Tanımlayıcı İstatistikleri

\begin{tabular}{|l|l|}
\hline Tanımlayıcı İstatistikler & Makale Sayısı \\
\hline Makale Sayısı & 439 \\
\hline Toplam Atıf Sayısı & 8645 \\
\hline Ortalama Atıf Sayısı & 19,96 \\
\hline h-index & 45 \\
\hline
\end{tabular}

Tablo 4 : Elektronik Ağızdan Ağıza İletişime Katkısı Olan İlk 25 Üniversite ve Makale Sayıları

\begin{tabular}{|l|l|l|}
\hline Sıra & Üniversite Adı & Makale Sayıs \\
\hline 1 & State University System Of Florida & 16 \\
\hline 2 & City University of Hong Kong & 11 \\
\hline 3 & California State University System & 10 \\
\hline 4 & Pennsylvania Commonwealth System of Higher Education Pcshe & 10 \\
\hline 5 & University of Valencia & 9 \\
\hline 6 & National Chengchi University & 8 \\
\hline
\end{tabular}


A. Eren - D. Eren 12/3 (2020) 2515-2530

\begin{tabular}{|l|l|l|}
\hline 7 & Penn State University & 8 \\
\hline 8 & Hong Kong Polytechnic University & 7 \\
\hline 9 & National Cheng Kung University & 7 \\
\hline 10 & Nevada System of Higher Education Nshe & 7 \\
\hline 11 & Purdue University & 7 \\
\hline 12 & Purdue University System & 7 \\
\hline 13 & University of Amsterdam & 7 \\
\hline 14 & University of Nevada Las Vegas & 6 \\
\hline 15 & California State Polytechnic University Pomona & 6 \\
\hline 16 & Hong Kong Baptist University & 6 \\
\hline 17 & Korea University & 6 \\
\hline 18 & Kyungpook National University & 6 \\
\hline 19 & National Taiwan University of Science Technology & 6 \\
\hline 20 & Ohio State University & 5 \\
\hline 21 & Seoul National University & 5 \\
\hline 22 & University of Central Florida & 5 \\
\hline 23 & University of Sevilla & 5 \\
\hline 24 & Autonomous University of Madrid & 5 \\
\hline 25 & Depaul University & 5 \\
\hline
\end{tabular}

Tablo 4'te Web of Science'da eWOM'un taranması sonucunda elektronik ağızdan ağıza iletişim alanına en fazla katkısı olan 25 üniversitenin alan ile ilgili yayınlanan makale sayısı ile birlikte verilmiştir. State University System of Florida 16 makale ile ilk sırada, City University of Hong Kong 11 makale ile ikinci sirada, California State University System ve Pennsylvania Common Wealth System of Higher Education Pcshe 10 makale yayını ile üçüncü ve dördüncü sırada oldukları görülmektedir. Sırasıyla National Chengchi University, Penn State University, University of Valencia, Hong Kong Polytechnic University, Nevada System of Higher Education Nshe, Purdue University, University of Nevada Las Vegas, University of Sevilla, California State Polytechnic University Pomona, Hong Kong Baptist University, Korea University, National Cheng Kung University, National Taiwan University of Scince Technology, Seoul National University, University of Amsterdam, Depaul University, Hanyang University, Kyungpook National University, Ohio State University, University of Central Florida ve University of Tehran ilk dört üniversiteyi takip etmektedir.

Tablo 5'te görüldüğü üzere makalelerin büyük çoğunluğu İngilizce yazılmıştır. Beş makale İspanyolca birer makale de Almanca ve Türkçe dillerinde yazılmıştır. Bilim dilinin İngilizce olması ve web of Science'da taranan dergilerinin yayın dillerinin İngilizce olması bunda en büyük etkendir.

Tablo 5: Makalelerin Dili

\begin{tabular}{|l|c|}
\hline Makale Dili & Makale Sayıları \\
\hline İngilizce & 432 \\
\hline İspanyolca & 5 \\
\hline Almanca & 1 \\
\hline Türkçe & 1 \\
\hline
\end{tabular}


Tablo 6'da görüldüğ̈̈ üzere araştırma konuları Web of Science tarafından 10 başlıkta sınırlandırılmıştır. Makalelerin 239'u iş ekonomisi, 95'i sosyal bilimler, 95'ı bilgisayar, 45'i bilgi bilimi, 43'ü psikoloji, 33'ü iletişim, 20'si telekomünikasyona, 12'si yönetim bilimi, 9'u çevre bilimi/ekoloji ve 7'si mühendislik bilimi ile ilgilidir.

Sosyal medya kullanıcılarının çoğalmasıyla birlikte çevrimiçi veri tabanlarını kullanma ihtiyacı artarken veri tabanı kullanımı veya sorgu yapılabilecek dil konularında uzman olmayan kullanıcı sayısı da artmaktadır (Bhalotia, Hulgeri, Nakhe, Chakrabarti \& Sudarshan, 2002). Bu yüzden elektronik ağızdan ağıza iletişim yönetimi ve elektronik ağızdan ağıza iletişimi genel konularının altında daha fazla çalışma olması beklenirken, bu konu başlıkları alt sıralarda yer almaktadır. Elektronik ağızdan ağıza iletişimin sayısı, içeriği ve elektronik ağızdan ağıza iletişim yapanın kimliği ile ilgili elektronik ağızdan ağıza iletişim konusundaki öncü çalışmaların incelenmesi hususunda pazarlamanın araştırma konuları içerisinde hiç yer almamış olması dikkat çekmektedir. Makalelerin çalışma alanları sisteme yazarlar tarafından girilmiştir. Çalışmalar incelendiğinde alanları tek bir alan olarak belirlenmiş olsa da çeşitli bilim dalları ile ilişkide oldukları tespit edilmiştir. Ana konu Tablo 6'daki konulardır. Elektronik ağızdan ağıza iletişim için yapılan taramada araştırma alanlarının iş ekonomisi, sosyal bilimler, bilgisayar, bilgi bilimi, psikoloji, iletişim, telekomünikasyon, yönetim bilimi, ekoloji ve mühendislik olduğu sonucuna varılmıştır.

Tablo 6: Araştırma Alanları

\begin{tabular}{|l|c|}
\hline Makalelerin Araştırma Alanları & Makale Sayısı \\
\hline İş ekonomisi & 239 \\
\hline Sosyal bilimler & 95 \\
\hline Bilgisayar & 95 \\
\hline Bilgi bilimi & 46 \\
\hline Psikoloji & 43 \\
\hline İletişim & 33 \\
\hline Telekominikasyon & 20 \\
\hline Yönetim bilimi & 12 \\
\hline Çevre bilimi/Ekoloji & 9 \\
\hline Mühendislik & 7 \\
\hline
\end{tabular}

Web of Science'da taranan gelişmiş bilim dizinleri SCI-EXPANDED, SSCI, A\&HCI, ESCI'dir. Bu bilim dizinlerinden Science Citation Index Expanded 1980'den günümüze, Social Sciences Citation Index 1980'den günümüze, Arts \& Humanities Citation Index 1975'den günümüze ve Emerging Sources Citation Index 2015'den günümüze varlıklarını sürdürmektedirler. Bu bilim dizinleri içerisinde eWOM ile ilgili makalelerin en fazla yer aldığı dizin Social Sciences Citation Index'dır. 249 makale SSCI de taranmış olup, 104 makale Science Citation Index Expanded da taranmıştır.

Tablo 7. WebofScience Bilim Dizini ve Dizinlerde Yayınlanan Makale Sayıları

\begin{tabular}{|l|c|}
\hline Web Bilim Dizinleri & Makale Sayıs \\
\hline Social Sciences Citation Index & 249 \\
\hline Science Citation Index Expanded & 104 \\
\hline Emerging Sources Citation Index & 86 \\
\hline
\end{tabular}

Tablo 8'de eWOM kelimesi taranarak incelenmiş makaleler içerisinde en çok makalesi olan 20 yazar verilmiştir. Katkısı olan yazarlar Okazaki, Abubakar, Ahn J, Bigne E, Chen YM, Cheunk CMK, Chong AYL, Ilkan M, Jalılvand MR, Khong KW, Kim J, Law R, Martinez-Torres MR, Matilla AS, Olmedilla M, Sanz-Blass 
A. Eren - D. Eren 12/3 (2020) 2515-2530

SToral SL ,Buzova D, Li X ve Tsao WC'dir. Sans Blas S. ve Okazaki S.'in beş makalesi bulunurken, diğerlerinin 4 makalesi mevcuttur. Bu tablo oluşturulurken sadece yazarlara ait en fazla makale sayısı olan 5 ve 4 sinırlılığ kullanılmıştır. 5 ve 4 makalesi olan yazar sayısı 20 iken 3 makale sayısını sınırlılığın içine eklendiğinde 50 yazarın olduğu tespit edilmiştir.

Tablo 8. eWOM'a Katkısı Olan Yazarlar ve Makale Sayıları

\begin{tabular}{|c|c|c|}
\hline Sira & Yazar & Makale Sayısı \\
\hline 1 & Okazakı S & 5 \\
\hline 2 & Sanz-Blas S & 5 \\
\hline 3 & Ahn J & 4 \\
\hline 4 & Bigne E & 4 \\
\hline 5 & Chen Ym & 4 \\
\hline 6 & Cheung Cmk & 4 \\
\hline 7 & Chong Ayl & 4 \\
\hline 8 & Ilkan M & 4 \\
\hline 9 & Jalılvand Mr & 4 \\
\hline 10 & Khong Kw & 4 \\
\hline 11 & Kım J & 4 \\
\hline 12 & Law $\mathrm{R}$ & 4 \\
\hline 13 & Martınez-Torres Mr & 4 \\
\hline 14 & Mattıla As & 4 \\
\hline 15 & Olmedilla M & 4 \\
\hline 16 & Abubakar Am & 4 \\
\hline 17 & Toral Sl & 4 \\
\hline 18 & Tsao Wc & 4 \\
\hline 19 & $\mathrm{Li}, \mathrm{X}$ & 4 \\
\hline 20 & Buzova D & 4 \\
\hline 21 & Lee, J & 3 \\
\hline 22 & Teng,S & 3 \\
\hline 23 & Chih, Wh & 3 \\
\hline 24 & Koo, Dm & 3 \\
\hline 25 & Wang, Ky & 3 \\
\hline 26 & Baek, H & 3 \\
\hline 27 & Qh, S & 3 \\
\hline 28 & Pai, My & 3 \\
\hline 29 & Lin, Z & 3 \\
\hline 30 & Phua, J & 3 \\
\hline 31 & Yang. J & 3 \\
\hline
\end{tabular}


A. Eren - D. Eren 12/3 (2020) 2515-2530

\begin{tabular}{|l|l|c|}
\hline 32 & Bilgihan, A & 3 \\
\hline 33 & Li, C & 3 \\
\hline 34 & Martin-Fuentes, E & 3 \\
\hline 35 & Wang, X & 3 \\
\hline 36 & Campo, S & 3 \\
\hline 37 & Hsu, Lc & 3 \\
\hline 38 & Bronner, F & 3 \\
\hline 39 & De Hoog, R & 3 \\
\hline 40 & Mishra, A & 3 \\
\hline 41 & Zhang, L & 3 \\
\hline 42 & Fang, Yh & 3 \\
\hline 43 & Kim, Eek & 3 \\
\hline 44 & Luo, C & 3 \\
\hline 45 & Chu, Sc & 3 \\
\hline 46 & Lee, Mko & 3 \\
\hline 47 & Litvin, Sw & 3 \\
\hline 48 & Gvili, Y & 3 \\
\hline 49 & Hsieh, Mt & 3 , \\
\hline 50 & Levy, S & 3 \\
\hline
\end{tabular}

Söz konusu 50 yazarın makale sayıları ve atıfları ve birbirleri olan ilişkileri temsili bağlantılar kurularak istatistiki analizlerle desteklenen bilgiler ile birlikte aşağıdaki haritada sunulmuştur. Haritada bulunan yuvarlakların büyüklügü atıf sayılarının büyüklüğünü temsil ederken renkler ise haritanın sağ alt köşesinde görüldüğü üzere yayın yılını temsil eder. Mordan sarıya doğru giden renk şeridinde en mor 2012 öncesini en sarı ise 2017 sonrasinı ifade eder.

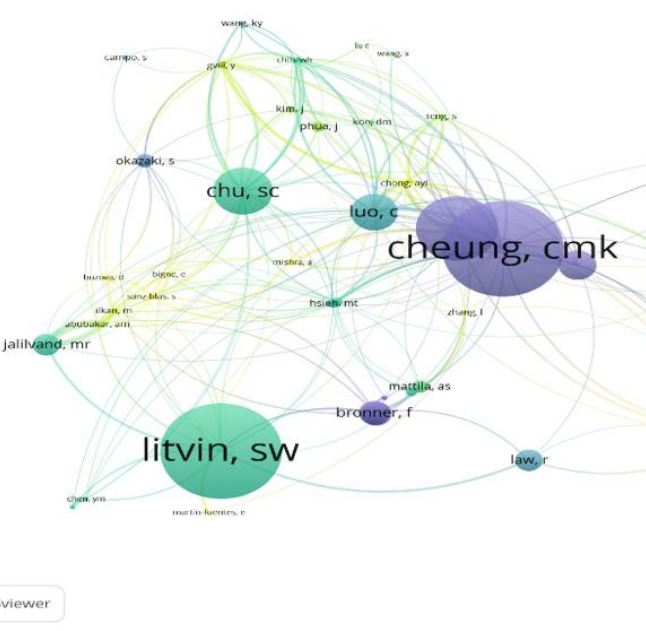

Harita 1: Üç Ve Daha Fazla Makalesi Olan Yazarlar, Atıf Analizleri Ve Ortak Ağ Haritası 


\section{A. Eren - D. Eren 12/3 (2020) 2515-2530}

Bütün makalelerin anahtar kelimeleri içerisinde en az 10 kez tekrar edilmiş 18 kelimenin aralarındaki temsili bağlantının haritası verilmiştir. Toplam anahtar kelime sayısı 1269 olup tekrar edilmiş kelimeler şöyledir. eWOM (140), social media (56), electronic word of mouth (45), electronic word-of-mouth (46), online reviews (27), trust (14), sentiment analysis (13), social networking sites (11), tripadvisor (10), facebook (11), purchase intention (12), user generate content (10), word-of-mouth (18), word of mouth (12), electronic word-of-mouth (ewom) (25), consumer behaviour (10), elaboration likelihood model (11) ve electronic word of mouth (ewom) (24) en çok kullanılan 18 kelimedir.

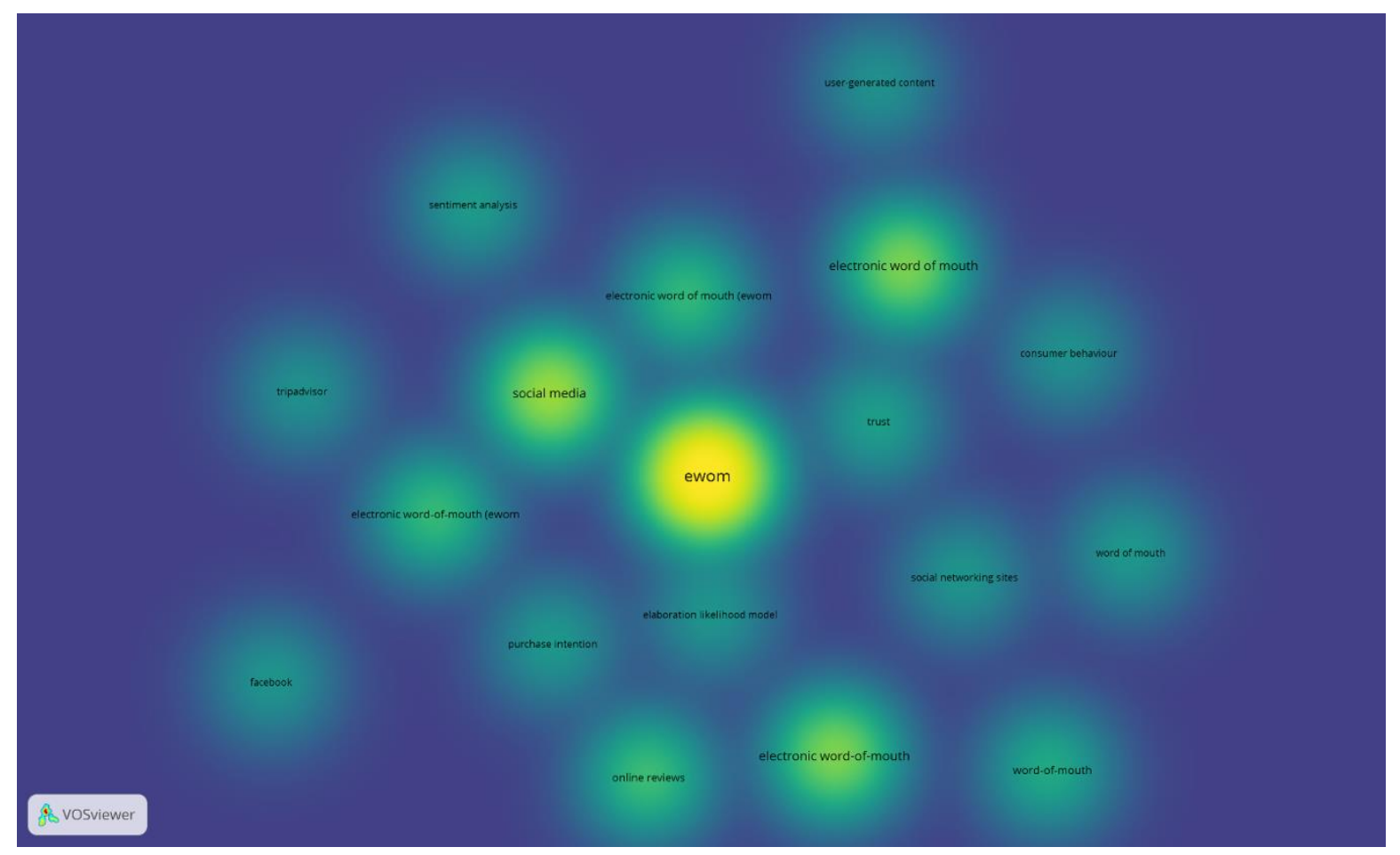

Harita 2: eWOM İle İlgili Yayınlarda Birlikte Kullanılan Anahtar Kelimelerin Yoğunluk Haritası

VOSviewer'a yüklenen bütün makalelerin özetleri incelenmiş en az 50 kez tekrarlanmış 27 kelimenin bir biri ile olan temsili bağları harita 4'te verilmiştir. Bütün makalelerin özetlerinde toplam 7569 kelime kullanıldığı görülmüştür. En çok kullanılan 27 kelime ise şöyledir; ağız 268, electronic word 253, ewom 273, metodoloji 82, orjinalik değeri 86 , çalışma 324, kelime 74 , pratik uygulamalar 74, makale 131, etkilemek 185, yorum 131, tüketici 162 , niyet 135 , ürün 100 , bilgi 129 , ilişki 119 , tutum 81 , model 154 , faktör 86 , araştırma 162 , sosyal medya 57, etki 128, kullanıcı 90, tüketici 76, veri 106, çeşit 76 ve etki (impact) 106 . Haritada en çok kullanılmış ewom anahtar kelimesinin yoğunluğunun sarı ve yuvarlaklığının daha büyük verildiği görülmektedir. Eğer 1000'e yakın kullanım olsaydı yuvarlak daha büyük ve rengi ise ortadan başlayarak kırmızıya doğru olacaktı. Ağızdan ağıza iletişim ifadesinin bir kelimesi olan "ağız" "kelime" "elektronik kelime" program tarafından tek bir kelime olarak algılandığından farklı bir anlam için kullanılmamış olsa dahi en çok tekrarlanan kelimeler arasında yer almıştır.

Atıf ağının tanımlanmasıyla yazarlar arasındaki bilgi alışverişinin sıklığını tanımlamak mümkün olabilmektedir (Barnett, Huh, Kim \& Park, 2011). Bu sebeple çalışmada 100'den fazla atıf almış 19 makalenin analizi ve aralarındaki temsili bağ harita 4'te sunulmuştur. Bu makaleler haritada Cheung (2012a), Park (2009), Hung (2007), Cheung (2012b), Chu (2011), Steffles (2009), Amblee (2011), Bronner (2011), Zhang (2010), Lee(2009), Park (2008b), Litvin (2008), Gruen (2006), See-To (2014), Jeong (2011), Cheung (2009), Doh (2009), Park (2008a) ve Cheung (2008) kısaltmaları kullanılmıştır. Maviden sarıya değişen renkler atıf sayılarını vermektedir. Yine haritada makalelerin her biri için olan yuvarlakların büyüklüğü atıf sayısına göre değişmektedir. En küçük yuvarlak en az atıfı en büyük yuvarlak en fazla olan atıfı temsil etmektedir. 
A. Eren - D. Eren 12/3 (2020) 2515-2530

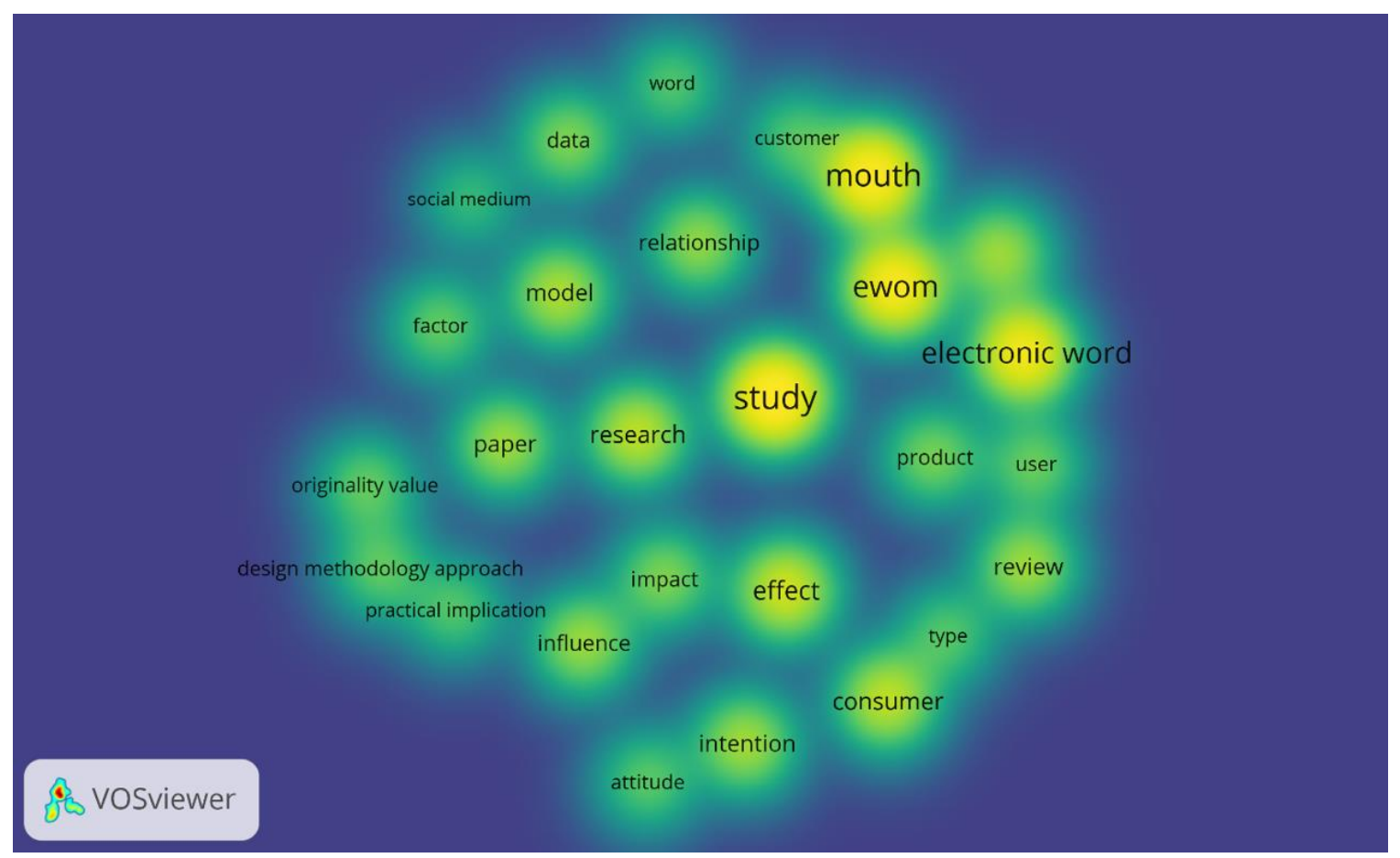

Harita 3: eWOM İle İlgili Yayınların Özetlerde Birlikte Kullanılan En Az 50 Kez Tekrarlanmış 27 Kelimenin Yoğunluk Haritası.

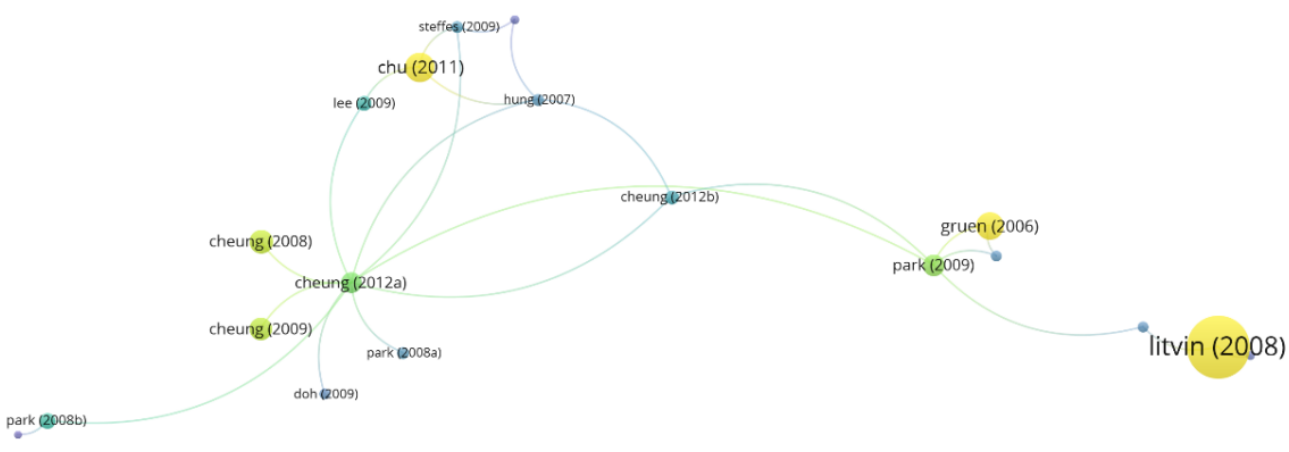

Harita 4: 100'den Fazla Atıf Almış Elektronik Ağızdan Ağıza İletişim Makalelerinin Birbirleri İle Olan Ağ Haritası

Makalelerin tam künyeleri Tablo 9'da verilmiştir. Listedeki çalışmaların verimliliklerinin daha net ifade edilebilmesi için toplam atıf sayıları eklenmiştir. Tablo 9 makalelerin yayımlandığı yıl baz alarak oluşturulmuştur. En fazla atıf harita 4'te en büyük yuvarlak ve sarı olarak verilmiş olan Litvin, Stephen W.; Goldsmith, Ronald E.; Pan, Bing, (2008), tarafından yazılmış Electronic word-of-mouth in hospitality and tourism management isimli makaledir. Bu makaleler eWOM alanına yön veren temel makaleler, diğer bir ifade ile literatürde en sık birlikte atıf yapılan makalelerdir. Harita 4 ve Tablo 9 konu ile ilgili ilk kez araştırma yapacak kişinin öncelikli okuması gereken makaleler listesi olarak değerlendirilebilir. Bibliyometrik çalışmaların varsayımı, kullanılan göstergelerin farklı bakış açıları göz önünde bulundurularak tam bir harita sağlayacak kadar temsili olduğudur, böylece her okuyucu kendi ilgi alanlarına göre daha ilginç olan belirli konulara odaklanabilir (Valenzuela Fernandez ve ark., 2018). Çalışmada oluşturulan tablolar ve haritalar 
A. Eren - D. Eren 12/3 (2020) 2515-2530

zaman içerisinde değişecek olabilir, ancak görsellerdeki görülebilir verimlilik ipuçları uzun süre aynı kalacaktır.

Tablo 9. 100'den Fazla Atıf Almış eWOM Makalelerin Künyeleri

\begin{tabular}{|c|c|c|}
\hline Sira & Künye & Atıf Sayısı \\
\hline 1 & $\begin{array}{l}\text { Cheung, Christy M. K.; Thadani, Dimple R.(2012a) The Impact Of Electronic } \\
\text { Word-Of-Mouth Communication: A Literature Analysis And Integrative Model, } \\
\text { Decision Support Systems, } 54 \text { (1) } 461-470\end{array}$ & 246 \\
\hline 2 & $\begin{array}{l}\text { Cheung, Christy M. K.; Lee, Matthew K. O. (2012b), What Drives Consumers to } \\
\text { Spread Electronic Word of Mouth In Online Consumer-Opinion Platforms, } \\
\text { Decision Support Systems, } 53 \text { (1) 218-225 }\end{array}$ & 165 \\
\hline 3 & $\begin{array}{l}\text { Chu, Shu-Chuan; Kim, Yoojung, (2011), Determinants of Consumer Engagement } \\
\text { In Electronic Word-Of-Mouth (eWOM) In Social Networking Sites, International } \\
\text { Journal of Advertising, } 30 \text { (1) Special Issue: } 47-75\end{array}$ & 350 \\
\hline 4 & $\begin{array}{l}\text { Amblee, Naveen; Bui, Tung, (2011), Harnessing the Influence of Social Proof in } \\
\text { Online Shopping: The Effect of Electronic Word of Mouth on Sales of Digital } \\
\text { Microproducts, International Journal of Electronic Commerce, } 16 \text { (2) 91-113 }\end{array}$ & 107 \\
\hline 5 & $\begin{array}{l}\text { Bronner, Fred; De Hoog, Robert, (2011) Vacationers and eWOM: Who Posts, } \\
\text { And Why, Where, And What?, Journal of Travel Research, } 50 \text { (1) 15-26 }\end{array}$ & 134 \\
\hline 6 & $\begin{array}{l}\text { Jeong, Eunha; Jang, Soocheong (Shawn) (2011), Restaurant Experiences } \\
\text { Triggering Positive Electronic Word-Of-Mouth (eWOM) Motivations, } \\
\text { International Journal of Hospitality Management, } 30 \text { (2) 356-366 }\end{array}$ & 111 \\
\hline 7 & $\begin{array}{l}\text { Zhang, Jason Q.; Craciun, Georgiana; Shin, Dongwoo (2010), When Does } \\
\text { Electronic Word-Of-Mouth Matter? A Study of Consumer Product Reviews, } \\
\text { Journal of Business Research, } 63 \text { (12) 1336-1341 }\end{array}$ & 136 \\
\hline 8 & $\begin{array}{l}\text { Park, Cheol; Lee, Thae Min, (2009), Information Direction, Website Reputation } \\
\text { and eWOM Effect: A Moderating Role of Product Type, Journal of Business } \\
\text { Research, } 62 \text { (1) } 61-67\end{array}$ & 256 \\
\hline 9 & $\begin{array}{l}\text { Steffes, Erin M.; Burgee, Lawrence E. (2009), Social Ties and Online Word of } \\
\text { Mouth, Internet Research, } 19 \text { (1) } 42-59\end{array}$ & 147 \\
\hline 10 & $\begin{array}{l}\text { Lee, Mira; Youn, Seounmi (2009), Electronic Word of Mouth (eWOM) How } \\
\text { eWOM Platforms Influence Consumer Product Judgement, International Journal } \\
\text { of Advertising, } 28 \text { (3) 473-499 }\end{array}$ & 183 \\
\hline 11 & $\begin{array}{l}\text { Cheung, Man Yee; Luo, Chuan; Sia, Choon Ling; et al. (2009), Credibility Of } \\
\text { Electronic Word-Of-Mouth: Informational And Normative Determinants Of On- } \\
\text { Line Consumer Recommendations, International Journal Of Electronic } \\
\text { Commerce, } 13 \\
\text { (4) 9-38 }\end{array}$ & 272 \\
\hline 12 & $\begin{array}{l}\text { Doh, Sun-Jae; Hwang, Jang-Sun (2009), How Consumers Evaluate eWOM } \\
\text { (Electronic Word-Of-Mouth) Messages, Cyberpsychology \& Behavior, } 122 \text { 193- } \\
197\end{array}$ & 193 \\
\hline 13 & $\begin{array}{l}\text { Park, Do-Hyung; Lee, Jumin (2008a), eWOM Overload And Its Effect On } \\
\text { Consumer Behavioral Intention Depending On Consumer Involvement, } \\
\text { Electronic Commerce Research And Applications, } 7 \text { Issue: } 4 \text { 386-398 }\end{array}$ & 142 \\
\hline 14 & $\begin{array}{l}\text { Park, Do-Hyung; Kim, Sara (2008b), The Effects Of Consumer Knowledge On } \\
\text { Message Processing Of Electronic Word-Of-Mouth Via Online Consumer } \\
\text { Reviews, Electronic Commerce Research And Applications, 7, } 4 \text { 399-410 }\end{array}$ & 193 \\
\hline
\end{tabular}




\begin{tabular}{|l|l|l|}
\hline 15 & $\begin{array}{l}\text { Litvin, Stephen W.; Goldsmith, Ronald E.; Pan, Bing, (2008), Electronic Word- } \\
\text { Of-Mouth In Hospitality And Tourism Management, Tourism Management, } \\
\mathbf{2 9} \text { Issue: } 3 \quad \text { 458-468 }\end{array}$ & 739 \\
\hline 16 & $\begin{array}{l}\text { Cheung, Christy M. K.; Lee, Matthew K. O.; Rabjohn, Neil, (2008), The Impact Of } \\
\text { Electronic Word-Of-Mouth - The Adoption Of Online Opinions In Online } \\
\text { Customer Communities, Internet Research, 18 (3) 229-247 }\end{array}$ & 276 \\
\hline 17 & $\begin{array}{l}\text { Hung, Kineta H.; Li, Stella Yiyan (2007), The Influence Of eWOM On Virtual } \\
\text { Consumer Communities: Social Capital, Consumer Learning, And Behavioral } \\
\text { Outcomes, Journal Of Advertising Research, 47 (4) 485-495 }\end{array}$ & 139 \\
\hline 18 & $\begin{array}{l}\text { Gruen, Tw; Osmonbekov, T; Czaplewski, Aj (2006), eWOM: The Impact Of } \\
\text { Customer-To-Customer Online Know-How Exchange On Customer Value And } \\
\text { Loyalty, Journal Of Business Research, 59 (4) 449-456 }\end{array}$ & 329 \\
\hline 19 & $\begin{array}{l}\text { See-To, Eric W. K.; Ho, Kevin K. W.(2014) Value Co-Creation And Purchase } \\
\text { Intention In Social Network Sites: The Role Of Electronic Word-Of-Mouth And } \\
\text { Trust - A Theoretical Analysis, Computers In Human Behavior, 31 182-189 }\end{array}$ & 100 \\
\hline
\end{tabular}

\section{SONUÇ ve TARTIŞMA}

Araştırmada, elektronik ağızdan ağza iletişim konusunun yer aldığı, Web of Science veritabanı tarafından indekslenen dergi makaleleri bibliyometrik özellikleri açısından analiz edilmiştir. Farklı yapılar (araştırma alanları, makalelerin atıf analizleri, en çok atıf almış yazarlar, anahtar kelime, araştırmaya katkısı en fazla olan ülkeler ve yayın dilleri) arasındaki ilişkiler görselleştirilmiştir. Böylelikle elektronik ağızdan ağıza iletişim konusundaki öncü çalışmalara ayrıntılı bir şekilde yer verilmiştir.

1975-2019 yılları arasındaki elektronik ağızdan ağıza iletişim ile ilgili yayınlar WoS Core Collection veritabanından bir savedrects dosyası şeklinde alınmış ve 439 yayın istatistiksel ve bibliyometrik analizler için kullanılmıştır. Bu çalışma da belge tipi olarak makale seçilmiş olup bir başka çalışmada bildiri, özet bildir, kitap özeti gibi belge türleri seçilerek yapılacak tarama ile karşılaştırma yapılması önerilebilir.

Web of Science veritabanında taranan makalelerin dışında Scopus vd. veri tabanlarında yapılacak aynı tarama ile bu çalışmanın karşılaştırmasının yapılması önerilebilir. Her ne kadar Web of Science çok fazla dergiyi kapsamına alsa bile Scopus veri tabanı da sosyal bilimler alanında yapılacak araştırmalar için önemli bir veri kaynağıdır. Yapılacak araştırmalarda Scopus veri tabanının kullanılması ile elde edilen bulguların yapılmış çalışmalardan elde edilen bulgular ile karşılaştırılmasının oldukça faydalı olacağı değerlendirilmektedir.

İstatiksel analizler sonucunda etkin yazarlar, üniversiteler ve ülkeler belirlenmiş; ayrıca, yazar sayısına göre makale dağılımları, atıf analizleri, yıllara göre makale sayılarının değişimleri ve en çok atıf alan yayınlara yer verilmiştir. Elektronik ağızdan ağıza iletişim konulu makalelere yapılan atıf 8786'dır. En çok 2018 yılında yazılmış makalelere atıf yapıldığı gözlemlenmiştir. En az atıf ise 2007 makalelerine olmuştur. Yayın sayısının yıllar bazında değişimi incelendiğinde, neredeyse her yıl, elektronik ağızdan ağıza iletişim alanında yayınlanan yayın sayısında bir artış olduğu saptanmışıı.

Atıf sayılarının dışında en çok atıf yapılmış makalelerin künyesi verilerek elektronik ağızdan ağıza iletişim ile ilgili araştırma yapacak kişinin ilk okuması gereken makalelerin listesi sunulmuştur.

Elektronik ağızdan ağıza iletişim katkısı olan 25 üniversite ve makale sayıları verilmiştir. En çok katkısı olan üniversite State University System of Florida'dır. 439 makalenin dilleri İngilizce, Almanca, İspanyolca ve Türkçe olup en fazla İngilizce yazıldığı tespit edilmiştir. Bu konuda en çok yayın yapan kurum ve araştırmacıların arasında Türkiye' den isimler yer almamaktadır.

Makalelere konu olmuş ve üzerine en çok makale yazılmış araştırma konusu "İş Ekonomisi"dir. "Yönetim bilimi" en az üzerine makale yazılmış konulardan biridir. Ancak Yönetim bilimi elektronik ağızdan ağıza iletişim ile doğrudan bağlantılıdır. Elektronik ağızdan ağıza iletişim alt konularından birisi elektronik ağızdan ağıza iletişim yönetimi olarak karşımıza çıkmaktadır. Az çalışılmış konu olması itibari ile yönetim bilimi üzerine yapılacak makalelerin sayısının artması literatüre katkı sağlayacaktır. Ayrıca çalışmalar incelendiğinde alanları tek bir alan olarak belirlenmiş olsa da çeşitli bilim dalları ile ilişkide oldukları tespit edilmiştir. Örneğin 439 makale içerisinde pazarlama temelli makalenin olmadığı söylenemez. "eWOM: The 


\section{A. Eren - D. Eren 12/3 (2020) 2515-2530}

impact of customer-to-customer online know-how exchange on customer value and loyalty" başlıklı makale iş ekonomisi konusu altında verilmiştir ve ilişkisel pazarlama ile de doğrudan ilişkilidir.

Makalelerin h indeksi de incelenmiş olup 45 makalenin en az 45 atfı mevcuttur sonucuna ulaşılmıştır. Web of Science kapsamına gelişmiş bilim indekslerinde yayınlanan makale sayılarına bakıldığında yarısından fazlasının Social Science Citation Index'te yayınlandığı sonucuna varılmıştır.

Elektronik ağızdan ağıza iletişime en çok katkısı olan yazarlar Okazakı, S. ve Sans-Blass, S.'dir. Sözü edilen yazarların her biri elektronik ağızdan ağıza iletişim konusunda beş makale yazmıştır. Üçten fazla makalesi olan yazarların atıf haritaları verilmiştir. Ayrıca bu harita ile makalelerde birbirlerine yapılmış atıflar bağlantı şeklinde karşımıza çıkmış olup birçok makalenin aynı konu üzerinde çalışma yapılırken birbirlerine atıf yaptıklarını gözler önüne serilmiştir.

En az on kez tekrar edilmiş on sekiz anahtar kelimenin kullanım yoğunluğuna göre bir haritalama yapılmış ve en çok kullanılan kelimelerin eWOM ve electronic word of mouth gibi farklı versiyonları ve bağlantılı kelimelerinin olduğu anlaşılmıştır. Özette en çok tekrar edilmiş kelimeler için aynı şeyi söylemek mümkündür. Ayrıca Vosviewer yazılımı özet ve anahtar kelimeleri tararken kelime öbeği olarak verilen electronic word of mouth içindeki kelimeleri ayrı ayrı değerlendirebilmektedir. Haritada word, mouth ve electronic word gibi kelimeler electronic word of mouth'un parçası olarak değerlendirilmelidir.

Elektronik ağızdan ağıza iletişim konusu ile ilgili yapılan araştırmaların anahtar kelimelerinde sıkça sosyal medya ifadesi kullanılmıştır. Sosyal medya, insanları sanal bir platformda bir araya getiren ağlardır. Blog, mikro bloglar, fotoğraf paylaşımı, video paylaşımı, ürün eleştirisi, şirket eleştirisi, seyahat tavsiyesi vb. şeklinde birçok farklı sosyal medya çeşidi bulunmaktadır. Çevrimiçi yorumların araştırmalarda daha fazla incelendiği görülmektedir.

Sosyal medya sitelerinden Tripadvisor ve Facebook anahtar kelimelerde en fazla yer alan sitelerdir. Tripadvisor ziyaretçilerin seyahat planlarında bilgi kaynağı olarak kullandıkları bir sitedir (Eren \& Çelik, 2017). Tripadvisor'ın araştırmalarda incelenmesi, söz konusu araştırmaların odağında turizm olduğunu göstermektedir. Turizm hareketlerine katılacak bireylerin hizmete veya işletmeye kolaylıkla ulaşamaması, ilgili destinasyon veya işletme hakkında yazılan kullanıcı yorumlarına ihtiyacını artırmaktadır. Bu alan tüketiciler için çok önemli olduğundan araştırmacıların ilgisini çekmektedir. Facebook dünyada en fazla kullanıcı sayısına sahip olan sosyal ağ olarak araştırmalara konu olmaktadır.

Satın alma niyeti, anahtar kelimeler içinde sıklıkla kullanılan bir araştırma alanı olmuştur. Ürünleri deneyimleyen tüketicilerin, potansiyel tüketicileri satın alma konusunda nasıl etkilediği oldukça ilgi çeken başka bir konu olmaktadır.

Anahtar kelimelerde duygu analizi ifadesinin yer alması, sosyal medya platformlarında bireylerin paylaşımda bulunurken yaşamış olduğu duyguların araştırmacılar tarafından incelendiğini göstermektedir. Farklı bir anahtar kelime yine araştırmaların tüketici davranışları konusuna eğildiğini göstermektedir.

İncelenen yayınların özetleri içinde kullanılan kelimelerin sıklıklarına bakıldığında, ilk olarak özetin temel amacı olan araştırmayı tanıtma doğrultusunda kullanılan kelimeler karşımıza çıkmaktadır. Araştırma, metodoloji, çalışma, uygulayıcılar için sonuçlar ve orijinallik gibi kelimeler bütün araştırmalarda kullanılabilecek ifadelerdir. Elektronik ağızdan ağıza iletişim konusunu inceleyen bu araştırmaların özetleri, elektronik ağızdan ağıza iletişim, tüketici, etki, bilgi ve tutum gibi kelimeleri sıklıkla içerdiğinden, araştırmaların tüketici davranışlarına yöneldiği tespit edilmiştir.

Çalışmada elde edilen bulguların, gelecekte elektronik ağızdan ağıza iletişim ile ilgili gerçekleştirilecek çalışmalarda konu ile ilgili anahtar kelimelerin, dergilerin ve referans gösterilecek kaynakların belirlenmesine katkı sağlayacağı düşünülmektedir.

Bundan sonraki araştırmalarda turizm sektörünü etkileyen Tripadvisor'dan farklı seyahat yorum siteleri incelenebilir. Türkiye ve yurtdışı kaynaklı seyahat yorum sitelerinin incelenmesi ve karşılaştırılması yapılabilir. Türkiye en çok turist çeken ilk on ülke içinde yer almaktadır ve turizm sektörü gelişmiş bir destinasyon olması sebebiyle turizm ve elektronik ağızdan ağıza iletişim konulu araştırmalara ihtiyaç olduğu ve uluslararası literatürde bu araştırmaların yer alabileceği görülmektedir. Elektronik ağızdan ağıza iletişim konusuna işletmeler açısından eğilerek yapılacak araştırmalar literatüre katkı sağlayabilme potansiyeline sahiptir. 


\section{KAYNAKÇA}

Barnett, G. A., Huh, C., Kim, Y., ve Park, H. W. (2011). Citations among communication journals and other disciplines: a network analysis. Scientometrics, 88(2), 449-469. https://doi.org/10.1007/s11192-011-03812

Bhalotia, G., Hulgeri, A., Nakhe, C., Chakrabarti, S., ve Sudarshan, S. (2002). Keyword searching and browsing in databases using BANKS. Proceedings 18th International Conference on Data Engineering, 431-440. https://doi.org/10.1109/ICDE.2002.994756

Blanco-Mesa, F., Merigó, J. M., \& Gil-Lafuente, A. M. (2017). Fuzzy decision making: A bibliometric-based review. Journal of Intelligent \& Fuzzy Systems, 32(3), 2033-2050. doi:10.3233/jifs-161640

Cancino, C., Merigó, J. M., Coronado, F., Dessouky, Y., \& Dessouky, M. (2017). Forty years of Computers \& Industrial Engineering: A bibliometric analysis. Computers \& Industrial Engineering, 113, 614629. doi:10.1016/j.cie.2017.08.033

Carl, W. J. (2006). What's All The Buzz about? Management Communication Quarterly, 19(4), 601-634. https://doi.org/10.1177/0893318905284763

Daugherty, T., ve Hoffman, E. (2014). eWOM and the importance of capturing consumer attention within social media. Journal of Marketing Communications, C. 20, ss. 82-102. https://doi.org/10.1080/13527266.2013.797764

Eren, R., ve Çelïk, M. (2017). Çevrimiçi Gastronomi İmajı: Türkiye Restoranlarının Tripadvisor Yorumlarının İçerik Analizi. Turizm Akademik Dergisi, 4(2), 121-138.

Hennig-Thurau, T., Gwinner, K. P., Walsh, G., ve Gremler, D. D. (2004). Electronic word-of-mouth via consumer-opinion platforms: What motivates consumers to articulate themselves on the Internet? Journal of Interactive Marketing, 18(1), 38-52. https://doi.org/10.1002/dir.10073

Hirsch, J. E. (2005). An index to quantify an individual's scientific research output. Proceedings of the National Academy of Sciences, 102(46), 16569-16572. https://doi.org/10.1073/pnas.0507655102

Husain, S., Zafar, M., \& Ullah, R. (2020). Ramadan and public health: A bibliometric analysis of top cited articles from 2004 to 2019. Journal of Infection and Public Health. doi:10.1016/j.jiph.2019.11.006

Li, W., \& Zhao, Y. (2015). Bibliometric analysis of global environmental assessment research in a 20-year period. Environmental Impact Assessment Review, 50, 158-166. https://doi.org/10.1016/j.eiar.2014.09.012

Merigó, J. M., Mas-Tur, A., Roig-Tierno, N., ve Ribeiro-Soriano, D. (2015). A bibliometric overview of the Journal of Business Research between 1973 and 2014. Journal of Business Research, 68(12), 2645-2653. https://doi.org/10.1016/j.jbusres.2015.04.006

Merigó, J. M., Cobo, M. J., Laengle, S., Rivas, D., \& Herrera-Viedma, E. (2018). Twenty years of Soft Computing: a bibliometric overview. Soft Computing.doi:10.1007/s00500-018-3168-z

Nebioğlu, O. (2019). Turizm ve Yiyecek Tüketimi: Uluslararası Alanyazın Üzerine Bibliyometrik Bir Analiz. Seyahat ve Otel İşletmeciliği Dergisi, 16(1), 71-88. https://doi.org/10.24010/soid.461702

Noyons, E. (2001). Bibliometric mapping of science in a science policy context. Scientometrics, 50(1), 83-98. https://doi.org/https://link.springer.com/content/pdf/10.1023\%2FA\%3A1005694202977.pdf

Park, D.-H., Lee, J., ve Han, I. (2007). The Effect of On-Line Consumer Reviews on Consumer Purchasing Intention: The Moderating Role of Involvement. International Journal of Electronic Commerce, 11(4), 125148. https://doi.org/10.2753/JEC1086-4415110405

Rodrigues, S. P., van Eck, N. J., Waltman, L., ve Jansen, F. W. (2014). Mapping patient safety: a large-scale literature review using bibliometric visualisation techniques. BMJ Open, 4(3), e004468. https://doi.org/10.1136/bmjopen-2013-004468

Smith, L. C. (1981). Citation analysis. Library Trends, 30(1), 83-106. https://doi.org/http://hdl.handle.net/2142/7190 
A. Eren - D. Eren 12/3 (2020) 2515-2530

Su, YB., Zhu, RF., Wang, C., Han, SF., Liu, H., Duan, ZG., (2020), Bibliometric analysis of Journal of Nursing Management from 1993 to 2018, Journal Of Nursing Management, 28/2, 317-331

Thelwall, M. (2008). Bibliometrics to webometrics. Journal of Information Science. https://doi.org/10.1177/0165551507087238

Tunç, M. (2015). H İndeksi Göstergesinin Sosyometrik Analizlere Uyarlanması. İstanbul Üniversitesi Sosyoloji Dergisi, 3(29), 425-440.

Valenzuela Fernandez, L. M., Nicolas, C., Merigó, J. M., \& Arroyo-Cañada, F.-J. (2019). Industrial marketing research. A bibliometric analysis (1990-2015). Journal of Business \& Industrial Marketing. doi:10.1108/jbim-07-2017-0167

Vishwakarma, P., \& Mukherjee, S. (2019). Forty-three years journey of Tourism Recreation Research: a bibliometric analysis. Tourism Recreation Research, 1-16. doi:10.1080/02508281.2019.1608066 